\title{
Right versus left transthoracic approach for lymph node-negative esophageal squamous cell carcinoma
}

\author{
Qilong $\mathrm{Ma}^{\dagger}$, Wengao Liư ${ }^{\dagger}$ Hao Long, Tiehua Rong, Lanjun Zhang, Yongbin Lin ${ }^{*}$ and Guowei Ma*
}

\begin{abstract}
Background: To compare the right and left transthoracic approach on the post-operative survival of patients with lymph node-negative esophageal squamous cell carcinoma.

Methods: Six hundred and ninety-five ESCC patients who underwent esophagectomy between 1990 and 2005 were retrospectively enrolled in the present study and were confirmed by histology to be of no lymph node metastasis. Those who had received neoadjuvant chemotherapy or radiotherapy were excluded from the study. Patients were divided into two groups, the left $(n=545)$ and right $(n=150)$ transthoracic groups. The follow-up duration ranged from 1 to 20 years with a mean of 7 years. Kaplan-Meier and univariate and multivariate Cox proportional hazards were used for analysis.

Results: 3- and 5-year CSS rates were $62.0 \%$ and $44.0 \%$ in the left group, while the corresponding figures in the right group were $56.0 \%$ and $40.0 \%(P<0.05)$. The overall survival for the two groups was significantly different $(P=0.045)$. Survival analyses were stratified by stages, which found that the favorable survival advantage was not present. When the survival curves were stratified by tumor locations, a significant difference was not revealed. Surgical approaches were regarded as one of the prognostic factors in the univariate analysis $(P=0.019)$. However, this significance could not be confirmed in multivariate Cox regression analysis $(P=0.193)$.
\end{abstract}

Conclusions: The left transthoracic approach is superior in some aspects to the right transthoracic approach regarding surgical and oncological outcomes in the treatment of lymph node negative ESCC.

Keywords: Transthoracic approach, Lymph node-negative, Esophageal cancer, Survival analysis

\section{Background}

Esophageal cancer (EC) is the eighth most common cancer and the sixth leading causes of cancer death worldwide [1]. The incidence of esophageal cancer, especially adenocarcinoma, has been on the increase in western countries [2]. In China, squamous cell carcinoma is the commonest histological subtype and accounts for over $95 \%$ of the cases $[3,4]$.

Surgery is the single most effective treatment with curative intent for esophageal carcinoma [5]. The commonest open surgical approaches include transthoracic and transhiatal esophageal resection. The transthoracic esophageal resection includes Ivor Lewis (laparotomy

\footnotetext{
* Correspondence: linyb@sysucc.org.cn; magw@sysucc.org.cn

${ }^{\dagger}$ Equal contributors

Sun Yat-sen University Cancer Center, Guangdong Esophageal Cancer

Institute, State Key Laboratory of Oncology in South China, 651

Dongfengdong Road, 510060 Guangzhou, China
}

and right thoracotomy), McKeown (right thoracotomy, laparotomy, and neck incision) and left transthoracic esophagectomy [6, 7]. We categorized these surgical approaches as left and right transthoracic approaches in our study.

A review of the Medicare database of the United States [8] showed that the mortality rates following esophagectomy ranged from $3.2 \%$ to $6.1 \%$, and the complication rates varied from $30 \%$ and $80 \%$ with an average of $50 \%$ [9]. However, the right transthoracic esophagectomy is preferred to that of the left especially in the western society because it provides excellent surgical exposure to the esophagus and regional lymph nodes. Despite this, the left transthoracic technique still serves as an effective alternative and is being advocated by many surgeons. Whether or not there is a difference regarding oncological outcome between the two approaches is not conclusive. 
Therefore, we well designed this study to compare thoroughly the clinical outcomes between the two groups for lymph node-negative esophageal squamous cell carcinoma (ESCC).

\section{Methods}

This retrospective study was performed by utilizing a database established at the Sun Yat-sen University Cancer Center, Guangzhou, China. We enrolled 695 ESCC patients who underwent esophagectomy in the Department of Thoracic Surgery between 1990 and 2005 and were confirmed by histology to be of no lymph node metastasis. Those who had received neoadjuvant chemotherapy or radiotherapy were excluded from the study. Patients were divided into two groups, namely, the left $(n=545)$ and right $(n=150)$ transthoracic groups. The follow-up duration ranged from 1 to 20 years, with a mean of 7 years. This study was approved by the Ethics Committee of Sun Yat-sen University Cancer Center.

The demographic data, surgical and oncological outcome were obtained from the established database. Baseline factors included sex, age, smoking history, alcohol consumption history, preoperative hemoglobin level, surgical duration, anastomosis method, tumor size, location, stage, and grade. Cancer staging was based on the American Joint Committee on Cancer (AJCC) staging manual (7th Edition) [10]. Because all the surgeries were completed before the publication of AJCC staging manual (7th Edition), it was challenging to verify the exact tumor locations according to the new criteria suggested by this version of staging manual. Fortunately, the distances from the superior incisor to esophageal lesions were well measured and recorded since every patient received gastroscopy routinely, and there figures could be used to estimate the tumor locations. In our study, tumors $15-20 \mathrm{~cm}$ distal to the superior incisor were considered as cervical location, while those $20-25 \mathrm{~cm}$, $25-30 \mathrm{~cm}$, and $30-40 \mathrm{~cm}$ distal to the incisor were considered as upper, middle, and lower thoracic locations, respectively. Survival time was defined as the time from surgery to death. To ensure that deaths were exclusively cancer-related, the patients who either died from other causes or were still alive at last follow-up were censored.

All the data were analyzed using SPSS Statistics Software (version 16.0, IBM SPSS, Inc.). The two-tailed KruskalWallis $\mathrm{H}$ test was used to obtain $P$ values. The 3 -year and 5-year cancer-specific survival (CSS) rates were obtained and compared by Life Table Analysis. Survival curves were generated, and the log rank test was used to determine the statistical significance of the difference between the two groups. Stratification analysis was applied to investigate further the influence of surgical approaches on ESCC of different stages and locations. $P$ value of less than 0.05 was considered to be statistically significant.

\section{The left thoracic approach}

The patient was placed in the right lateral decubitus position. A traditional posterolateral incision was made along the sixth intercostal space in the left hemithorax. Mediastinal regional lymph nodes were resected in en bloc fashion with anatomical dissection of the esophagus. The gastric conduit was then harvested via transdiaphragmatic approach along with abdominal lymph node clearance. Gastro-esophageal anastomoses were constructed in the thorax of $518(95.0 \%)$ patients and on the neck of $27(5.0 \%)$ patients.

\section{The right thoracic approach}

Firstly, the patient was placed in left lateral decubitus position. A standard right posterolateral thoracotomy was placed along the fifth intercostal space in the right hemithorax. The esophagus along with the regional lymph nodes in the mediastinal region was removed. Then, the patient was re-positioned in a supine position. A second upper midline laparotomy was performed from the umbilicus to the xyphoid. With preservation of the right gastroeploic artery, the gastric conduit was harvested along with regional lymph nodes clearance in the abdominal region. After a third incision had been made extending along the sternocleidomastoid muscle $6 \mathrm{~cm}$ cephalad from the sternal notch through the platysma, the stomach was then drawn up to the neck through the chest. Finally, gastro-esophageal anastomoses were constructed in the left neck of 134 (89.3\%) patients. For the remaining 16 (10.7\%) patients who received Ivor-Lewis approach, their gastro-esophageal anastomoses were created in the right pleural cavity.

\section{Results}

\section{Patient and surgical characteristics}

Six hundred and ninety-five ESCC patients were enrolled in this study, of which 545 (78.4 \%) and 150 (21.6\%) patients underwent the left and right transthoracic approaches, respectively. $70.8 \%$ of the patients $(n=492)$ were male while $29.2 \%(\mathrm{n}=203)$ were female. Mean age was 55.7 years in the left group and 56.9 years in the right group $(P=0.192)$. In the left group, most patients' $(74.3 \%, \mathrm{n}=405)$ lesions located at the middle third of the esophagus, followed by tumors in the lower third of the esophagus $(22.9 \%, \mathrm{n}=125)$; whilst most patients' lesions in the right group sat at the middle third of the esophagus $(53.3 \%, n=80)$, followed by tumors in the upper third of the esophagus $(42.0 \%, \mathrm{n}=63$, overall $P<0.001$ ). Baseline characteristics of our cohort are summarized in Table 1. Operation durations were significantly different between the left and right transthoracic approaches with the mean time of 189 and $270 \mathrm{~min}$ respectively $(P<0.001)$. Greater intraoperative blood loss was observed in the right transthoracic group compared to the left group $(P<0.001)$. The incidence of postoperative complications was significantly higher in the 
Table 1 Baseline characteristics of patients grouped by surgical approach

\begin{tabular}{|c|c|c|c|}
\hline Characteristic & $\begin{array}{l}\text { Left transthoracic } \\
\text { approach }(n=545)\end{array}$ & $\begin{array}{l}\text { Right transthoracic } \\
\text { approach }(n=150)\end{array}$ & $P$ \\
\hline Sex & & & 0.995 \\
\hline Male & $386(70.6 \%)$ & 106 (70.7 \%) & \\
\hline Female & $159(29.4 \%)$ & $44(29.3 \%)$ & \\
\hline Average age & $55.66 \pm 9.85$ & $56.91 \pm 8.42$ & 0.192 \\
\hline Smoking history & 324 (59.4 \%) & 89 (59.3 \%) & 0.980 \\
\hline Drinking history & $109(20.0 \%)$ & $28(18.7 \%)$ & 0.716 \\
\hline $\begin{array}{l}\text { Preoperative } \\
\text { hemoglobin }\end{array}$ & $134.33 \pm 18.65$ & $132.49 \pm 17.38$ & 0.222 \\
\hline Preoperative FEV1 & $2.42 \pm 3.50$ & $2.37 \pm 0.70$ & 0.086 \\
\hline Duration of surgery & $189.24 \pm 50.41$ & $270.83 \pm 68.38$ & $<0.001$ \\
\hline $\begin{array}{l}\text { Blood loss during } \\
\text { surgery }\end{array}$ & $257.79 \pm 126.56$ & $297.96 \pm 129.00$ & $<0.001$ \\
\hline $\begin{array}{l}\text { Location of } \\
\text { anastomosis }\end{array}$ & & & $<0.001$ \\
\hline Cervical & $27(5.0 \%)$ & $134(89.3 \%)$ & \\
\hline Intrathoracic & $518(95.0 \%)$ & 16 (10.7\%) & \\
\hline Length of tumor & $4.81 \pm 1.96$ & $4.67 \pm 1.79$ & 0.288 \\
\hline Pathological stage & & & 0.336 \\
\hline la & 48 (8.8 \%) & $11(7.3 \%)$ & \\
\hline $\mathrm{lb}$ & $258(47.3 \%)$ & $67(44.7 \%)$ & \\
\hline Ila & 239 (43.9 \%) & $72(48.0 \%)$ & \\
\hline Location of tumor & & & $<0.001$ \\
\hline Upper third & $15(2.8 \%)$ & $63(42.0 \%)$ & \\
\hline Middle third & 405 (74.3 \%) & $80(53.3 \%)$ & \\
\hline Lower third & $125(22.9 \%)$ & 7 (4.7\%) & \\
\hline Method of anastomosis & & & 0.006 \\
\hline Manual & $50(9.2 \%)$ & $124(82.7 \%)$ & \\
\hline Mechanical & $495(90.8 \%)$ & 26 (17.3\%) & \\
\hline $\begin{array}{l}\text { Grade of differentiation } \\
\text { of tumor }\end{array}$ & & & 0.102 \\
\hline High & $213(39.1 \%)$ & $44(29.3 \%)$ & \\
\hline Middle & $219(40.1 \%)$ & $74(49.3 \%)$ & \\
\hline Low & 113 (20.7 \%) & 32 (21.3\%) & \\
\hline Number of resected $\mathrm{LNs}^{\mathrm{a}}$ & $9.18 \pm 5.48$ & $9.61 \pm 8.02$ & 0.171 \\
\hline $\begin{array}{l}\text { Postoperative } \\
\text { complications }\end{array}$ & $73(13.4 \%)$ & $40(26.7 \%)$ & $<0.001$ \\
\hline
\end{tabular}

FEV1 forced expiratory volume in 1 second

LNs lymph nodes

former $(26.7 \%$ vs. $13.4 \%, P<0.001)$. In particular, higher chance of anastomotic leak $(P<0.001)$, incision infection $(P<0.001)$, and respiratory complications $(P=$ 0.044) in the right transthoracic group were demonstrated in our study (Table 2). There were no significant differences regarding gender, age, smoking history, alcohol consumption history, preoperative hemoglobin level, tumor location, size, stage, and grade between the two groups.
Table 2 Incidence of postoperative complications in ESCC patients treated by the left or right transthoracic approach

\begin{tabular}{lccr}
\hline Complication & $\begin{array}{c}\text { Left approach } \\
\text { group [number(\%)] }\end{array}$ & $\begin{array}{c}\text { Right approach } \\
\text { group [number(\%)] }\end{array}$ & $P$ \\
\hline Anastomotic fistula & $10(1.8)$ & $18(12.0)$ & $<0.001$ \\
Anastomotic stenosis & $14(2.6)$ & $7(4.7)$ & 0.155 \\
$\begin{array}{l}\text { Incision site infection } \\
\text { Injury of recurrent }\end{array}$ & $2(0.4)$ & $8(5.3)$ & $<0.001$ \\
$\begin{array}{l}\text { laryngeal nerves } \\
\text { Chylothorax }\end{array}$ & $4(0.7)$ & $4(2.7)$ & 0.075 \\
$\begin{array}{l}\text { Pneumothorax } \\
\begin{array}{l}\text { Complication of } \\
\text { respiratory tract }\end{array}\end{array}$ & $12(2.2)$ & $2(1.3)$ & 0.303 \\
$\begin{array}{l}\text { Complication of } \\
\text { cardiovascular system }\end{array}$ & $7(1.3)$ & $3(2.0)$ & 0.574 \\
\hline
\end{tabular}

\section{Survival analysis}

3- and 5-year CSS rates were $62.0 \%$ and $44.0 \%$ in the left group, while the corresponding figures in the right group were $56.0 \%$ and $40.0 \%$ respectively $(P<0.05)$. Similarly, the specific cancer survival for the two groups was significantly different $(P=0.045)$ (Fig. 1). Survival analyses were stratified further in terms of tumor stages, which found that the favorable survival advantage was not particularly present (Fig. 2). When the survival curves were stratified by tumor locations, a significant difference was not revealed between the two groups (Fig. 3). Surgical approaches were regarded as one of the prognostic factors in the univariate analysis $(P=0.019)$. However, this significance could not be confirmed in multivariate Cox regression analysis $(P=0.193)$ (Tables 3 and 4$)$.

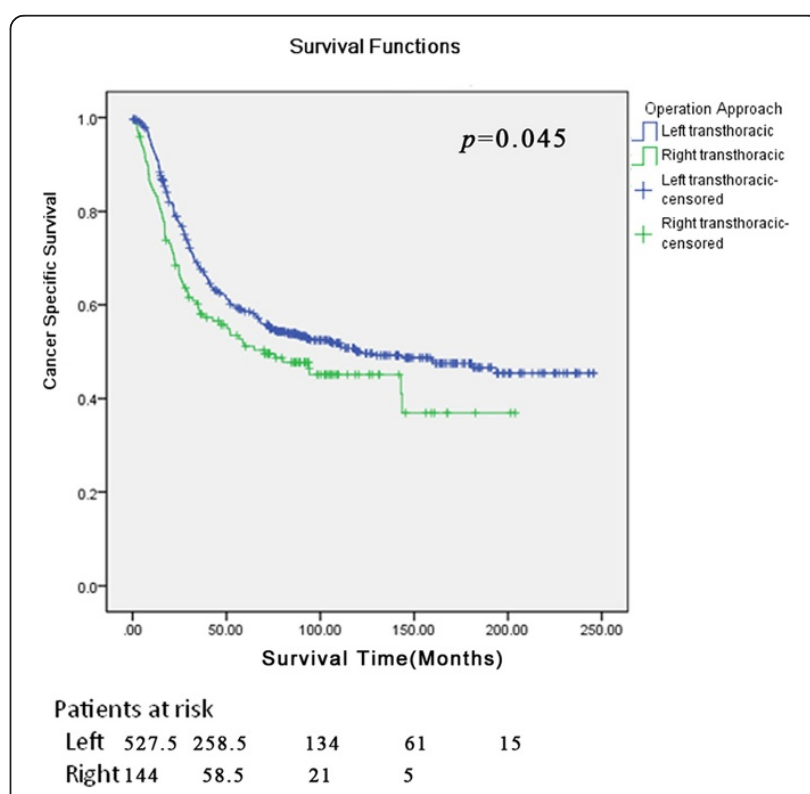

Fig. 1 Overall survival curves. The cancer specific survival for the two groups was significant different $(P=0.045)$ 

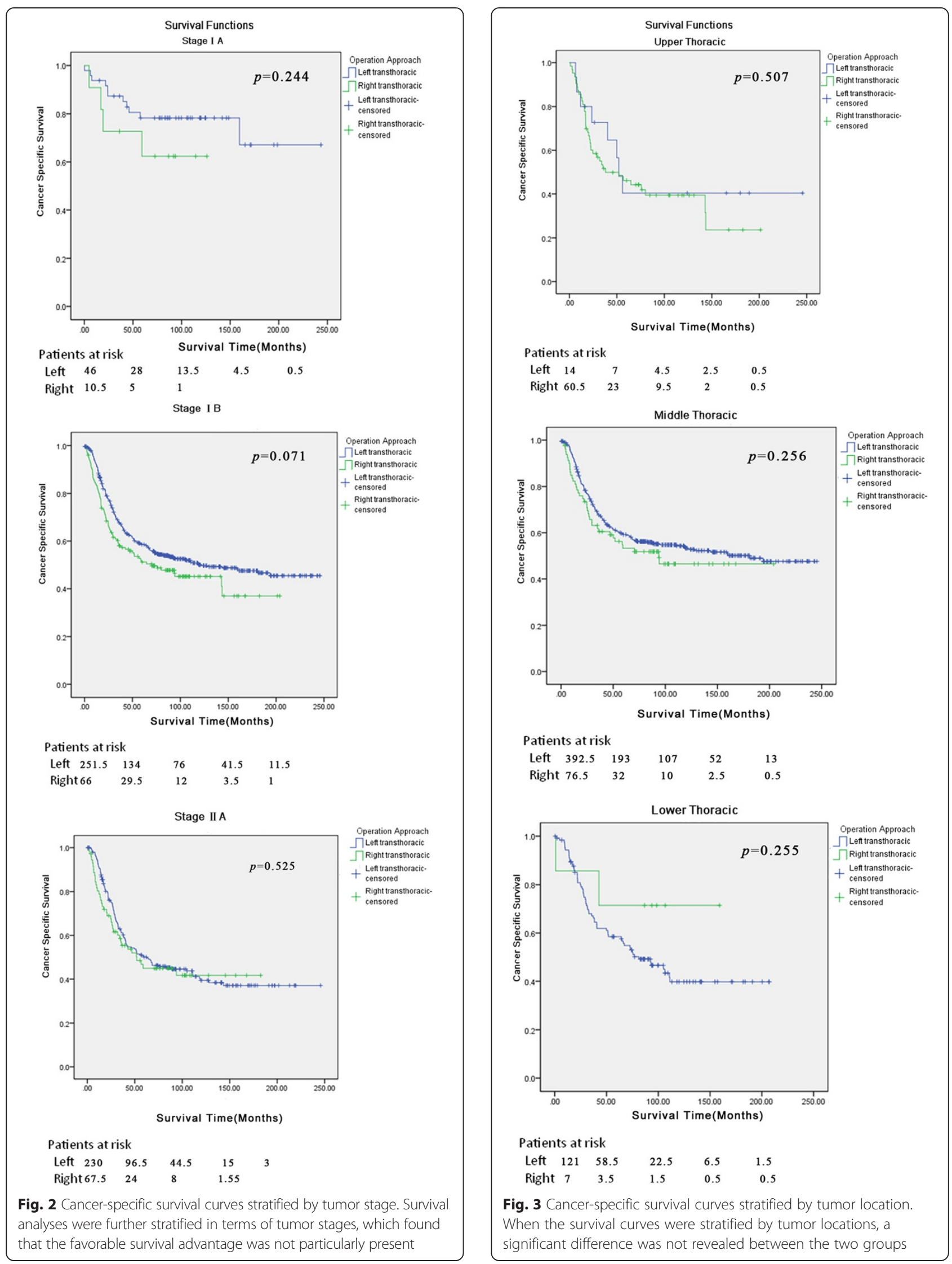
Table 3 Possible prognostic factors and relative risks

\begin{tabular}{lrcc}
\hline Possible prognostic factors & \multicolumn{1}{l}{$P$} & Hazard ratio & $\begin{array}{l}95 \% \text { Confidence } \\
\text { interval }\end{array}$ \\
\hline Age & 0.003 & 1.108 & $1.006-1.030$ \\
Smoking history & $<0.001$ & 1.601 & $1.273-2.014$ \\
Drinking history & $<0.001$ & 1.687 & $1.321-2.155$ \\
Duration of surgery & 0.039 & 1.002 & $1.000-1.003$ \\
Blood loss & 0.140 & 1.001 & $1.000-1.001$ \\
during surgery & & & \\
Tumor staging & $<0.001$ & 1.470 & $1.231-1.755$ \\
Tumor location & 0.249 & 0.887 & $0.724-1.087$ \\
Operation approach & 0.019 & 1.101 & $1.016-1.193$ \\
Location of anastomosis & 0.081 & 0.808 & $0.635-1.026$ \\
Method of anastomosis & 0.731 & 0.955 & $0.733-1.244$ \\
Complications & 0.132 & 0.812 & $0.619-1.065$ \\
\hline
\end{tabular}

\section{Discussion}

Esophageal cancer is one of the leading causes of cancer-related mortality worldwide [1]. The prevalence of esophageal cancer, especially adenocarcinoma, has increased in western countries [2]. In China, the squamous cell carcinoma is the most common histological subtype and accounts for over $95 \%$ of the cases [1].

Radical surgery is still the single most important modality in the multidisciplinary treatment of esophageal cancer. However, there are still many controversies surrounding the surgical resection of esophageal cancer way. No matter which kind of operation method chosen, the most important factoris that the surgical techniques chosen should have the following features: simple operation process, small trauma to the patient, fewer complications after surgery, removal of the tumor or the lymph nodes to the greatest extent. Some surgeons advocated the transhiatal esophagectomy for its lower morbidity and mortality with an inadequate lymphadenectomy. Previous studies showed that the optimum extent of lymph node resection is significantly associated with long-term survival after surgery, the group after transthoracic esophageal resection in cleaning the number of lymph nodes is greater than the transhiatal esophageal

Table 4 Survival differences after multivariate Cox proportional hazard regression analysis

\begin{tabular}{lccc}
\hline Item & $\begin{array}{c}P \text { by Cox } \\
\text { regression }\end{array}$ & Hazard ratio & $\begin{array}{l}95 \% \text { Confidence } \\
\text { interval }\end{array}$ \\
\hline Age & 0.011 & 1.016 & $1.004-1.028$ \\
Smoking history & 0.028 & 1.314 & $1.030-1.677$ \\
Drinking history & 0.001 & 1.556 & $1.201-2.015$ \\
Duration of surgery & 0.207 & 1.001 & $0.999-1.003$ \\
Tumor staging & 0.000 & 1.441 & $1.205-1.723$ \\
Operation approach & 0.193 & 1.064 & $0.969-1.168$ \\
\hline
\end{tabular}

resection group [11-13]. Choice of surgical techniques, like three-incision transthoracic esophagectomy with three-field lymph node dissection would depend on the patient's condition and the surgeon's individual preference [14]. The surgical approaches include left and right transthoracic approaches brought into the current study are the most common used in China. For tumors located in the middle or lower thoracic esophagus, some surgeons advocated left transthoracic esophagectomy rather than the right one, the left approach has many advantages in the treatment of middle or lower third esophageal carcinoma, especially with regard to the lower incidence of postoperative complications and shorter hospital stay $[15,16]$. There were also some researches demonstrate that the Ivor-Lewis procedure can be performed with lower rates of postoperative complications and more lymph node retrieval. Then we want to find the clinical outcomes for lymph node-negative esophageal squamous cell carcinoma (ESCC) [17].

Postoperative mortality for esophageal carcinoma, as reported in the literature, ranges from $0 \%$ to $10 \%$ Septicemia, secondary to anastomotic leak and pneumonia among all the relevant complications, are the primary causes of death. The average morbidity rate was reported to be $40.3 \%$, varying from $26.1 \%$ to $80.4 \%$. Overall 5 year CSS rate was revealed to be between $40 \%$ and $50 \%$ [18]. On the other hand, the overall incidence of tumor recurrence is approximately $14 \%$ [19-22]. We only enrolled the ESCC patients without lymph node metastasis in this comparison study, as a more homogeneous population with less confusing parameters would make our conclusion more specific and reliable.

Our study found that postoperative CSS rate was better in the left than the right transthoracic group. When the data were stratified, the survival advantage favoring the left transthoracic approach was only present for stage Ib tumors and tumors in the middle third of the esophagus. These survival differences may have resulted from several factors.

Firstly, related anatomies and surgical exposure are dramatically different between the two approaches. Admittedly, the right transthoracic approach could provide excellent surgical exposure to the esophagus and its drainage lymphatic areas. However, with the left thoracotomy, most of the thoracic field's lymph nodes could also be accessed; however, there might be some interference from the aortic arch. The manipulation of abdominal field is slightly challenging but still accessible after the diaphragm is widely opened. This technique, if used correctly, could offer satisfactory surgical exposure for sufficient tumor and lymph node resection in a single incision. Some researchers found that lymph node metastasis was more common in the patients with tumors in the middle or lower segments of the esophagus, and the 
metastases were disseminated all the way from the cervical to abdominal areas [23]. Therefore, adequate exposure and resection are critical for ESCC patients.

Secondly, surgical time was significantly different between the left and right transthoracic approaches, with the mean time of 189 and $271 \mathrm{~min}$, respectively $(P<0.001)$. It could be easily understood that the need for re-positioning the patients and two or three incisions would naturally make the right transthoracic surgery longer in the operation time. The drawback of prolonged surgical duration, if any, would mean the exposure of patients to higher anesthesia-related risks.

Moreover, the current study showed that postoperative complication rates were higher in the right group than those in the left group $(26.7 \%$ vs. $13.4 \%, P<0.001)$. We found that the incidence of anastomotic leak, incision infection, and respiratory complications were more common in the right transthoracic group. More incisions in the right transthoracic approach would result in more severe post-operative pain and analgesia that is more intensive, which in turn would increase the chances of infection. Anastomosis is more frequently constructed in the upper thorax or the neck in the right transthoracic approach, which may contribute to a higher tension on the anastomosis. However, the occurrence of complications is multi-factorial, like acute inflammatory reaction and anesthetic factors; therefore, further research needs to be carried out before we can substantiate our claim.

According to the outcomes of univariate and multivariate Cox regression analyses, the surgical approach is one of the factors that significantly influences prognosis.

The strengths and limitations of our study should be considered while interpreting these results. The strengths include a large sample of consecutive patients from a wellmaintained database and an efficient record system containing abundant tumor information such as tumor grade and stage. Furthermore, we conducted detailed stratified analyses regarding tumor stages and locations in our study, and multivariate analysis was used to explore potential impact factors.

A retrospective study, even when well designed, would inevitably have limitations. Our study included only patients with ESCC and excluded those with esophageal adenocarcinoma. This indicates that our conclusion would not be applicable in the regions where the esophageal adenocarcinoma is prevalent. Because all the surgeries were completed before the publication of AJCC staging manual (7th Edition), it was challenging to verify the exact tumor locations according to the new criteria suggested by this version of staging manual. We could only roughly estimate the tumor locations by categorizing the distances from the superior incisor to esophageal lesions recorded in gastroscopy, without given consideration to some factors like patient's height.

\section{Conclusions}

In conclusion, after a careful comparison, we found that the left transthoracic approach is not in anyway inferior to the right transthoracic. Our study revealed that it is superior, in some aspects, to the right transthoracic approach regarding surgical and oncological outcomes in the treatment of lymph node negative ESCC.

\section{Competing interests \\ The authors declare that they have no competing interests.}

\section{Authors' contributions}

QM carried out the studies and drafted the manuscript. WL participated in the design of the study and also performed the statistical analysis. HL, LZ, TR, YL and GM conceived our research topic. YL and GM also participated in the design coordination, and drafting of the manuscript. All authors read and approved the final manuscript.

\section{Acknowledgments}

This work was supported by the Fundamental Research Funds for the Central Universities (No. 09YKPY51),the Science and Technology Planning Project of Guangdong Province, China (No. 2010B31500010), the Science and Technology Planning Project of Guangdong Province, China (No. 2012B031800463) and the Science and Technology Planning Project of Guangdong Province, China (No. 2013B022000040).

Received: 12 March 2015 Accepted: 4 September 2015

Published online: 18 September 2015

\section{References}

1. Siegel R, Naishadham D, Jemal A. Cancer statictics, 2013. CA Cancer J Clin. 2013;63(1):11-30.

2. Thrift AP, Whiteman DC. The incidence of esophageal adenocarcinoma continues to rise: analysis of period and birth cohort effects on recent trends. Ann Oncol. 2012;23:3155-62.

3. He B, Yin B, Wang B, Xia Z, Chen C, Tang J. MicroRNAs in esophageal cancer. Mol Med Report. 2012;6:459-65.

4. Lin Y, Su X, Su H, Lin P, Long H, Zhang L, et al. Prediagnostic smoking and postoperative survival in lymph node-negative esophagus squamous cell carcinoma patients. Cancer Sci. 2012;103:1985-8.

5. Mariette C, Piessen G. Oesophageal cancer: how radical should surgery be? Eur J Surg Oncol. 2012;38:210-3.

6. Churchill ED, Sweet RH. Transthoracic resection of tumors of the esophagus and stomach. Ann Surg. 1942;115:897-920.

7. Lewis I. The surgical treatment of carcinoma of the oesophagus; with special reference to a new operation for growths of the middle third. $\mathrm{Br} J$ Surg. 1946;34:18-31

8. Lapar DJ, Stukenborg GJ, Lau CL, Jones DR, Kozower BD. Differences in reported esophageal cancer resection outcomes between national clinical and administrative databases. J Thorac Cardiovasc Surg. 2012;144:1152-7.

9. Raymond D. Complications of esophagectomy. Surg Clin North Am. 2012;92:1299-313.

10. Edge SB, Compton CC. The American Joint Committee on Cancer: the 7th edition of the AJCC cancer staging manual and the future of TNM. Ann Surg Oncol. 2010; 17(6):1471-4.

11. Ma GW, Situ DR, Ma QL, Long H, Zhang $\sqcup$, Lin P, et al. Three-field vs two-field lymph node dissection for esophageal cancer: a meta-analysis. World J Gastroenterol. 2014;20(47):18022-30.

12. Hulscher JB, Tijssen JG, Obertop H, van Lanschot JJ. Transthoracic versus transhiatal resection for carcinoma of the esophagus: a meta-analysis. Ann Thorac Surg. 2001;72:306-13.

13. Tong D, Law S. Extended lymphadenectomy in esophageal cancer is crucial. World J Surg. 2013;37(8):1751-6.

14. Nozoe T, Kakeji Y, Baba H, Maehara Y. Two-field lymphnode dissection may be enough to treat patients with submucosal squamous cell carcinoma of the thoracic esophagus. Dis Esophagus. 2005;18:226-9.

15. Tachibana M, Kinugasa S, Shibakita M, Tonomoto Y, Hattori S, Hyakudomi R, et al. Surgical treatment of superficial esophageal cancer. Langenbecks Arch Surg. 2006;391:304-21. 
16. Ma J, Zhan C, Wang L, Jiang W, Zhang Y, Shi Y, et al. The sweet approach is still worthwhile in modern esophagectomy. Ann Thorac Surg. 2014; 97(5):1728-33.

17. Li B, Xiang J, Zhang Y, Li H, Zhang J, Sun Y, et al. Comparison of Ivor-Lewis vs Sweet esophagectomy for esophageal squamous cell carcinoma: a randomized clinical trial. JAMA Surg. 2015; 150(4):292-8.

18. Situ DR, Wei W, Lin P, Long H, Zhang L, Fu J, et al. Do Tumor Grade and Location Affect Survival in Esophageal Squamous Cell Carcinoma? Survival Analysis of 302 Cases of pT3NOMO Esophageal Squamous Cell Carcinoma. Ann Surg Oncol. 2013;20:580-5.

19. Sugiyama M, Morita M, Yoshida R, Ando K, Egashira A, Takefumi O, et al. Patterns and time of recurrence after complete resection of esophageal cancer. Surg Today. 2012;42:752-8.

20. Yamamoto Y, Yamai H, Seike J, Yoshida T, Takechi H, Furukita Y, et al. Prognosis of esophageal squamous cell carcinoma in patients positive for human epidermal growth factor receptor family can be improved by initial chemotherapy with docetaxel, fluorouracil, and cisplatin. Ann Surg Oncol. 2012;19:757-65.

21. Watson TJ. "Open" esophagectomy. J Gastrointest Surg. 2011:15:1500-2.

22. Tanaka H, Ohira M, Kubo N, Muguruma K, Yamashita Y, Sawada T, et al. Association of location of lymph node metastases with postoperative recurrence of esophageal squamous cell carcinoma. Anticancer Res. 2012:32:3421-6,

23. Takeuchi H, Kawakubo H, Takeda F, Omori T, Kitagawa Y. Sentinel node navigation surgery in early-stage esophageal cancer. Ann Thorac Cardiovasc Surg. 2012;18:306-13.

\section{Submit your next manuscript to BioMed Central and take full advantage of:}

- Convenient online submission

- Thorough peer review

- No space constraints or color figure charges

- Immediate publication on acceptance

- Inclusion in PubMed, CAS, Scopus and Google Scholar

- Research which is freely available for redistribution 